\title{
Contamination Level (Water Quality) Assessment and Agro-ecological Risk Management of Shitalakshya River of Dhaka, Bangladesh
}

\section{Husna Israt Pia ${ }^{1}$, Marufa Akhter ${ }^{1}$, Supria Sarker ${ }^{1}$, Masud Hassan ${ }^{1 *}$, Sadique Rayhan ABM ${ }^{2}$, Md Mazharul Islam ${ }^{3}$ and Md Arafat Hassan ${ }^{4}$}

${ }^{1}$ Department of Soil, Water and Environment, University of Dhaka, Dhaka, Bangladesh

${ }^{2}$ Coastal and Ocean Management Institute, Xiamen University, Xiamen, China

${ }^{3}$ Department of Botany, University of Dhaka, Dhaka, Bangladesh

${ }^{4}$ Department of Geography and Environment, University of Dhaka, Dhaka, Bangladesh

*Corresponding author: Masud Hassan, Department of Soil, Water, and Environment, University of Dhaka, Bangladesh, Tel: +880 2-9661900 extn. 7471; E-mail: masudhassanswe1112@gmail.com

Received date: December 22, 2017; Accepted date: January 17, 2018; Published date: January 23, 2018

Copyright: @ $2018 \mathrm{Pia} \mathrm{HI}$, et al. This is an open-access article distributed under the terms of the Creative Commons Attribution License, which permits unrestricted use, distribution, and reproduction in any medium, provided the original author and source are credited.

\begin{abstract}
This study evaluates the chemical properties of Shitalakshya River water bodies based on its chemical parameters such as Total Suspended Solids (TSS), pH, Electic Conductivity (EC), Total Dissolved Solids (TDS), Dissolved Oxygen (DO), Biological Oxygen Demand (BOD), Chemical Oxygen Demand (COD), Total Nitrogen (N), Chlorine $(\mathrm{Cl})$, Total Phosphorous $(\mathrm{P})$, Sulfur $(\mathrm{S})$, Potassium (K). To do this chemical analysis, pre-monsoon and postmonsoon seasons were considered to collect the samples from this river. This analysis shows that Total dissolved solids (TSS) of this river in both seasons have crossed the standard limit announced by $\mathrm{WHO}$. The $\mathrm{pH}$ is less enough in the pre-monsoon season and in post monsoon it is up to the standard value. EC and Phosphorous both have crossed the standard value of drinking water in the Shitalakshya River. Nitrogen is too much less although it is a vital element. TDS, DO, BOD, COD, Cl, and $\mathrm{S}$ are approximately under the range of standard limits. The parameters that are high should be reduced in a proper treatment method so that this water can be used both for agricultural and drinking purposes.
\end{abstract}

Keywords: Chemical analysis; Agricultural; River; Total dissolved solids

\section{Introduction}

Water is one of the vital components in the earth and has a strong correlation between water and all kinds of life to sustain. Despite its importance, water is the most poorly managed in the developing countries [1]. The environment, economic growth and progress of Bangladesh are all highly influenced by water. Climate and physiography of the country is highly responsible for the availability of surface and ground water. The surface water of the country is unprotected from industrial waste, agricultural pesticides, and municipal wastewater. The water quality not only depends on the water itself but also depends on the toxic substances into the other ecosystem. The rivers around the Dhaka city are highly contaminated [2]. The water quality of Surrounding river of Dhaka city is worse than other sources of water quality of the country [3-5]. On the others hand, the water quality is much acceptable than treated waste water from the pagla sewage treatment plant, Dhaka [5,6]. The sources of water pollution come from river erosion, Soil erosion, losing soil fertility status, Application of pesticides and so on [7-11].

River pollution has become a hot environmental issue in urban areas specially in developing countries like Bangladesh. From the liberation of Bangladesh due to rapid growth of population, unplanned city expansion, industrialization and urbanization the rivers surrounding the capital city including Shitalakkshya have been facing serious pollution [12].
In Bangladesh, one of the Distributary Rivers of Brahmaputra is Shitalakshya. It was famous for the muslin industry in the past. Initially, it flows to the southwest direction. Later, it changes its path to the east of Narayanganj and then it comes to at one place with Dhaleswari near Kalagachhiya. Banar River is its upper course's portion. The length of this river is 68 miles or 110 kilometers long near Narayanganj, the width is $300 \mathrm{~m}$. The flow of this river is 74 cubic meters per second while measured at Demra [2]. The Shitalakhya has already changed its course twice in the past. Due to the change, the flow of water has been indirectly affected. Jamuna river channel was the main through which the flow of the Brahmaputra was carried away in the 21st century. In the past, it took a path to the west near the Garo Hills and then turned to Dewanganj of the south-east part. The Shitalakhya branch was occurred while passing Jamalpur and Mymensingh area and the main flow of Brahmaputra ran to the Dhaleshwari. Brahmaputra was accompanied by the Shitalakhya Riverand then fell into Dhaleshwari [2,13].

Due to this important location, many industries and factories are established at Shitalakhya river bank. This industry doesn't even practice the treatment method of toxic water and waste water. Hence, this huge amount of toxic and waste water ends up in the Shitalakhya River directly or indirectly by illegal discharging method. Also, municipal and domestic sewage sludge from the urban areas of Narayanganj are fallen into this river without treatment. The water from Shitalakhya River is used tremendously by the people living near it for their daily works such as washing, bathing etc. As a result, the impact of pollution is increasing day by day at a higher rate [14]. The industrial effluents and wastes carry various toxic substances as well as heavy metals. The agrochemical wastes contain toxic substances accompanying with nitrogenous elements and germs. Shitalakhya 
Page 2 of 4

River is greatly affected by these harmful elements and becomes bound to act as their sink. Moreover, the toilets made by the people living in the slums of Narayanganj pollute the river system by carrying out the harmful micro-organisms which creates serious hazards to environment and aquatic life and causes many problems to human health. People use this river water for their daily cooking, drinking and bathing purposes [15]. From the data monitored by the DoE it is demonstrated that the dissolved oxygen concentration in the Shitalakhya River varies from 2.1 to $2.9 \mathrm{mg} / \mathrm{l}$ [16]. It is also informed that the PH ranges between 7.1 to 6.5 at 1981 to 1990 . Data from Bangladesh Center for Advanced Studies showed that the EC of Shitalakhya river was $110 \mathrm{mg} / \mathrm{l}$ in previous years but during 1998, it increases upto $140 \mathrm{mg} / \mathrm{l}$ due to the harmful industrialization and agricultural activities [17]. TDS increases from 216 to $446 \mathrm{mg} / \mathrm{l}$. The standard limits of COD, TSS and DO had been crossed because of various textile and leather industries which dump their effluents and chemical wastes in the Shitalakhya River. Besides, the concentration level of chromium, lead, zinc and cadmium were also higher their permissible limits [17].

To figure out about the deterioration of chemical properties of the river water and sediments around the Dhaka city, some studies have been carried out in Bangladesh [15]. These present studies show that the industrial effluents and trace metals heavily affect the major rivers of Dhaka city including Shitalakshya River. Besides, many experiments have been conducted on the impacts of anthropogenic sources of the river based environmental conditions. In the year of 2007, a study was held regarding the assessment on risk and water quality of Shitalakshy a because of the influence of industrial effluents. As the industrial chemical wastes contained in the water bodies and sediments of Shitalakshya has a great influence on the agricultural aspects of its nearest area, it is a major concern for now a day. This study exposes the chemical contamination on the affected area and a comparison among the existing and standard limits of the various parameters.

To show the chemical analysis of the water bodies of Shitalakshya river. Comparing between the standard limits and existing limits and the states of agro-ecological risk of Shitalakshya river. To know result and degree of water pollution of Shitalakshya river and to verify in what extent the contamination is being spreaded and how it is affecting the total area surrounding this river. The work is of great importance and of scientific stipend. It deals with an interesting topic on the contamination of rivers and the elimination of the agro-ecological risks in their adjacent areas. The chemical analysis of the river before the monsoon comes and after it passes. It notes important variations of the different chemical parameters analyzed and makes a correlation between the agricultural activities and the analyzed indicators.

\section{Materials and Methods}

During pre-monsoon (2015) and a post-monsoon period (2016), Each sample is the composite of twenty sub-samples to minimize error and heterogeneity. The high-density PVC bottles (Merck) used for sampling were thoroughly cleaned by rinsing with $8 \mathrm{M} \mathrm{HNO}_{3}$ and deionized water followed by repeated washing with effluent sampled so as to avoid contamination [16]. Samples were collected from just below the effluent surface also to avoid floating contaminants. Aeration during sampling was avoided as far as possible. Immediately after collection samples were tested for $\mathrm{pH}, \mathrm{DO}, \mathrm{BOD}$ and COD. The analysis was acidified with concentrated $\mathrm{HNO}_{3}(5 \mathrm{ml} / \mathrm{l})$. Suspended solid was determined gravimetrically [18]. $\mathrm{pH}, \mathrm{EC}, \mathrm{DO}$ and TDS of the sample were determined by using $\mathrm{pH}, \mathrm{EC}, \mathrm{DO}$ and TDS-meter respectively. Organic carbon was estimated by Walkely and Black's wet oxidation and multiplied by 1.724 to get organic matter content. The COD was estimated titrimetrically [16]. The BOD test was done by measuring $\mathrm{O}_{2}$ concentration in the samples before and after incubation in the dark at $200^{\circ} \mathrm{C}$ for 5 days [13]. Total Nitrogen was determined by the Kjeldahl method. Total Phosphorus was determined by the yellow color method. Sulphur was determined by Spectrophotometer method, potassium was determined by flame photometer method. Chloride was determined by titrimetric analysis.

\section{Results}

It is very important to know that these contaminations resulting from different industrial effluents or wastes seriously affects the sources of drinking water and implicitly the agricultural cultures (Table 1).

\begin{tabular}{|l|l|l|l|l|l|l|l|l|l|l|l|l|l|l|l|}
\hline Parameters & TSS (Mg/L) & pH & EC (S/m) & TDS (ppm) & DO & BOD & COD & Total N & CI & P & S (ppm) & K \\
\hline Pre-monsoon & 118 & 5.6 & 116.6 & 112.3 & 1.2 & 4.56 & 8.85 & 0 & 4.02 & 401.2 & 8.25 & 4.31 \\
\hline a1 & 116 & 5.6 & 112.2 & 111.5 & 1.1 & 4.46 & 8.72 & 0 & 3.91 & 400 & 7.35 & 3.99 \\
\hline a2 & 119 & 5.5 & 115.3 & 113.4 & 1 & 4.66 & 8.92 & 0 & 4.11 & 392.4 & 8.36 & 4.4 \\
\hline a3 & 102 & 6.6 & 215.2 & 98.6 & 1.52 & 3.12 & 6.06 & 0 & 3.51 & 39 & 10 \\
\hline Post Monsoon & 101 & 6.6 & 212.2 & 96.2 & 1.42 & 3.01 & 6.07 & 0 & 3.49 & 38 & 10.52 & 3.3 \\
\hline a1 & 103 & 6.7 & 200.3 & 99.3 & 1.63 & 3.13 & 6.02 & 0 & 3.48 & 38 & 11.31 & 3.5 \\
\hline a2 & 102 &
\end{tabular}

Table 1: The following tables are representing different values of chemical analysis.

TSS: Total Suspended Solids are the solids in water trapped by a filter which include organic and inorganic materials such as silt, sewage, and decaying plants. It also includes animal parts and industrial wastes. Suspended solids in water are easily noticeable other than anything else. From the above-experimented chart we can see that in pre-monsoon season, TSS ranges from 116-119 mg/l. On the other 
hand, in the post-monsoon season, the range varies from 101-103 mg/l in the Shitalakshya River. Since there is a standard limit for each parameter, the TSS should be in between $50-100 \mathrm{ppm}[19,20] . \mathrm{pH}$ is known as the measure of alkalinity or acidity of water-soluble substances. It stands for potential of Hydrogen. Water in the $\mathrm{pH}$ can be affected by the chemicals contained by it. It is an important indicator of water that changes chemically. In general, water with a low $\mathrm{pH}$ (less than 6.5) could be acidic and soft. A water with a $\mathrm{pH}$ of greater than 8.5 can indicate that the water is hard. In the pre-monsoon season the $\mathrm{pH}$ ranges from 5.5- 5.6 and in the post-monsoon season, it becomes 6.6-6.7 in this river. The normal range for $\mathrm{pH}$ in the surface water system is 6.5 to 8.5 and for groundwater system, it is 6 to 8.5 . In the drinking water, the $\mathrm{pH}$ should be 6.5-8-5 [19,20].

EC: The electrical conductivity of water identifies the total amount of solids dissolved in water. The electrical conductivity of the water depends on the water temperature. The higher the temperature, the higher the electrical conductivity would be. This experimented chart on Shitalakshya River shows that in the pre-monsoon season the electrical conductivity of water ranges from $112.2-116.6 \mathrm{~S} / \mathrm{m}$ and in post monsoon season $200.3-215.2 \mathrm{~S} / \mathrm{m}$. The standard value for EC is $0-3.00 \mathrm{ppm}$ [19]. Total dissolved solids include inorganic salts such as calcium, magnesium, potassium, chlorides, and sulfates; and also, some small amounts of organic matter that are dissolved in water. TDS in water originates from various natural sources. In the pre-monsoon season of the Shitalakshya River, the total dissolved solids vary from $111.5-113.4 \mathrm{ppm}$ and in post monsoon season it is 96.2-99.3 ppm. The permissible limit for TDS in the drinking water quality is 500-2000 ppm which is announced by WHO in $2008[19,20]$.

Dissolved oxygen is the amount of oxygen dissolved in a water body such as river, lake or stream. It is vital for underwater life as aquatic creatures need to breathe. From the chart analyzed on the chemical parameters of Shitalakshya River, it is known that the DO ranges from $1.0-1.2 \mathrm{mg} / \mathrm{l}$ in pre-monsoon and $1.42-1.63 \mathrm{mg} / \mathrm{l}$ in post monsoon season. The standard limit for DO is supposed to be $5.00 \mathrm{ppm}[19,20]$. Biochemical oxygen demand is the measure of the quantity of oxygen used by the microorganisms during the oxidation of organic matter in that sample. The aerobic biological organisms break down the organic material present in a water body at a certain temperature. In the Shitalakshya River, the BOD range is $4.46-4.66 \mathrm{mg} / \mathrm{l}$ in the premonsoon season and $3.01-3.13 \mathrm{mg} / \mathrm{l}$ in post monsoon season. For drinking water quality, the acceptable limit considered by WHO is 5.00 ppm for BOD $[19,20]$.

Chemical oxygen demand is an indicative measure of the quantity of oxygen which can be consumed by reactions of oxidizing soluble and particulate organic matter in water. Similar to BOD, it provides an indication to the assessment of discharging wastewater will have on the surrounding environment. In the pre-monsoon season, the COD range is $8.72-8.92 \mathrm{mg} / \mathrm{l}$ and in post monsoon, it is $6.02-6.07 \mathrm{mg} / \mathrm{l}$ in the Shitalakshya River. The permissible limit for COD is $10 \mathrm{ppm}[19,20]$. Nitrogen is one of the most abundant elements which support the growth of algae and aquatic plants, which supply food and habitat for fish, shellfish and smaller organisms that live in water. But sometimes the high amount of nitrogen in the air and water can be harmful because it indicates pollution of the environment. In the Shitalakshya River, we can see from the experimental data that in pre-monsoon and post-monsoon season, the amount of Nitrogen is $0.00 \mathrm{ppm}$ in both cases. But it is assumed that there should be a standard limit for Nitrogen and it is supposed to be in between 15-30 ppm [19,20].
Chlorine is one of the most important elements needed for the living beings. Chlorine gas mixed with water in particularly controlled amounts kills microbiological organisms and bacteria in the water. From the drinking water guidelines announced by WHO it is known that the standard value of Chlorine is $250 \mathrm{ppm}[19,20]$. But in the Shitalakshya River, the amount of Chlorine is 3.91-4.11 ppm in premonsoon season and 3.48-3.51 ppm in post monsoon season. Phosphorous is a vital element for all the living beings, especially for plant life. But if the quantity of phosphorous gets much higher in the water body it speeds up eutrophication of that river and lake. The standard limit of phosphorous for drinking water quality is 4-20 ppm $[19,20]$. In the pre-monsoon season the range of phosphorous is 392.4-401.2 ppm and in post monsoon, it is $39-38 \mathrm{ppm}$ in the Shitalakshya River. Sulfur is an important element found in the earth crust which is essential for human health and works as a source of nutrition in many ways. Sometimes sulfur gets into groundwater in the form of sulfates when the sulfite ores are oxidized. In the drinking water, the acceptable limit of sulfur is $250 \mathrm{ppm}$ declared by WHO $[19,20]$. But from the above data we can see that the range of sulfur in pre-monsoon season is 7.35-8.36 ppm and in the post-monsoon season it rises up to $10.0-11.31 \mathrm{ppm}$ in the Shitalakshya River. Potassium in drinking water is low enough not to be a concern for healthy individuals. It is an important element considered as an electrolyte and nutrient. In the Shitalakshya River potassium range varies from 3.99-4.40 ppm in pre-monsoon season and 3.3-3.5 ppm in the post-monsoon season [21-23].

\section{Conclusion}

This study reveals that the Shitalakshya River has an enormous effect on the agro-ecological diversity of the nearest area of this river. The chemical analysis of the various parameters of this river is done in a systematic way so that the risk assessment is clearly understood. The contamination from the various industrial effluents and wastes are extremely affecting the agricultural and daily usable water sources through the Shitalakshya River.

\section{References}

1. Fakayode SO (2005) Impact of industrial effluents on water quality of the receiving Alaro River in Ibadan, Nigeria. Ajeam-Ragee 10: 1-13.

2. Majumdar RC (1971) History of Ancient Bengal. Reprint 2005, Tulshi Prakashani, Kolkata, pp: 3-4.

3. Haque S, Rayhan AS, Islam MM, Sultana Z, Nargis A, et al. (2017) Assessment of Irrigation Water Quality of Pabna District (North-Western Part) of Bangladesh for Securing Risk-Free Agricultural Production. American Journal of Water Science and Engineering 3: 67-71.

4. Trisha TH, Aktar M, Hassan M, Shamsad S (2017) An Investigation of Geo-Hydro-Chemistry and Physiochemical Properties of Irrigation Water Quality of Faridpur District, Bangladesh.

5. Mahmud MA, Hussain KA, Hassan M, Jewel AR, Shamsad SZKM (2017) Water quality assessment using physiochemical parameters and heavy metal concentrations of circular rivers in and around Dhaka city, Bangladesh. International Journal of Water Research 7: 23-9.

6. Hassan M, Hassan R, Mahmud MA, Pia HI, Hassan MA, et al. (2017) Sewage Waste Water Characteristics and Its Management in Urban Areas- A Case Study at Pagla Sewage Treatment Plant, Dhaka. Urban and Regional Planning 2: 13-16.

7. Hassan MA, Ratna SJ, Hassan M, Tamanna S (2017) Remote Sensing and GIS for the Spatio-Temporal Change Analysis of the East and the West River Bank Erosion and Accretion of Jamuna River (1995-2015), Bangladesh. Journal of Geoscience and Environment Protection 5: 79-92. 
Citation: Pia HI, Akhter M, Sarker S, Hassan M, Rayhan ABMS, et al. (2018) Contamination Level (Water Quality) Assessment and Agroecological Risk Management of Shitalakshya River of Dhaka, Bangladesh. Hydrol Current Res 9: 292. doi:10.4172/2157-7587.1000292

Page 4 of 4

8. Hassan M, Hassan R, Pia HI, Hassan MA, Ratna SJ, et al. (2017) Variation of Soil Fertility with Diverse Hill Soils of Chittagong Hill Tracts, Bangladesh. International Journal of Plant \& Soil Science 18: 1-9.

9. Hassan M, Ahmed AA, Hassan MA, Nasrin R, Rayhan AB, et al. (2017) Changes of Soil Fertility Status in Some Soil Series of Tista Floodplain Soils of Bangladesh, during 1996-2016. Asian Research Journal of Agriculture 5: 1-9.

10. Ahmed AA, Hassan M, Ahmed SU, Rahman MK (2017) Fertility Status on Some Tista Floodplain Soils of Bangladesh. International Journal of Scientific \& Engineering Research 8: 579-582.

11. Hassan M, Hassan R, Haque S, Sultana Z, Aktar M (2017) Improvement of purification method for diazinon from soil matrix. International Journal of Agriculture, Environment and Bioresearch 2: 230-240.

12. Hossain MS (2011) Time to save the Turag from pollutin. The Daily Star, Internet Edition.

13. Murshed MM (2012) Shitalakshya River. In: Islam S, Jamal AA (eds.) Banglapedia: National Encyclopedia of Bangladesh. 2nd edn. Asiatic Society of Bangladesh.

14. WARPO (2000) Environment, National Water Management Plan Project, Ministry of Water Resource, Government of Bangladesh.

15. Ahmed AU, Reazuddin M (2000) Industrial Pollution of Water Systems in Bangladesh. In: Rahman AA, Huq S, Conway GR (eds.) Environmental System of Surface Water Systems of Bangladesh. University Press Limited, Dhaka, Bangladesh, pp: 175-178.
16. Saad MS (2000) Personal Communication, Surface Water Modeling Centre (SWMC), Dhaka, Bangladesh.

17. BCAS (2000) Pollution Study, Management of Aquatic Ecosystem through Community Husbandry (MACH), Dhaka, Bangladesh.

18. BIWTA (2011) Development Project Proposal (DPP) for Construction of Infrastructural Facilities on Evicted Foreshore Land under Dhaka, Narayanganj and Tongi River Port Area. Project Document, Dhaka: Ministry of Shipping, Government of the People's Republic of Bangladesh.

19. WHO Geneva (2008) Guidelines for drinking water quality (electronic resource). 3rd edn. Incorporating 1 st and 2nd agenda, Volume 1, Recommendations, p: 53.

20. WHO (1998) Guidelines for drinking water quality. 2nd edn. Recommendation. World Health Organization, Geneva 1: 30-113.

21. Ahmed SU (2003) Dhaka A Study in Urban History and Development 1840-1921. Academic Press and Publishers Limited, Dhaka.

22. Ahmed F (2009) The shifting dialogue between the historical city of Dhaka and River Buriganga in the peer reviewed Proceedings SAUD (Sustainable Architecture and Urban Development) at Tripoli Libya November I: 29-44.

23. Naushad AM, Fazle E, Didar-Ul-Alam M (2007) Risk and Water Quality Assessment overview of River Sitalakhya in Bangladesh. Academic Open Internet Journal, Technical College, Bourgas. 